\title{
TITLE:
}

\section{$<$ NOTE>Masturbation with a Tool by an Infant Male Chimpanzee}

$\operatorname{AUTHOR}(S)$ :

Nakamura, Michio

\section{CITATION:}

Nakamura, Michio. <NOTE>Masturbation with a Tool by an Infant Male Chimpanzee. Pan Africa News 2018, 25(1): 2-4

ISSUE DATE:

2018-06

URL:

http://hdl.handle.net/2433/233027

RIGHT:

Copyright (C) Pan Africa News. 


\title{
Masturbation with a Tool by an Infant Male Chimpanzee
}

\author{
Michio Nakamura \\ Graduate School of Science, Kyoto University, Japan \\ (E-mail:nakamura@jinrui.zool.kyoto-u.ac.jp)
}

\section{INTRODUCTION}

Here I report a case of "masturbation" with a tool by a wild infant chimpanzee. More accurately, the infant male inserted his erect penis into a wadge discarded by an adult male and performed several thrusts, as if he was copulating with the wadge. The observed "masturbation" did not involve ejaculation, because infant chimpanzees are unable to ejaculate. A similar behavior, i.e., rubbing the penis against a piece of fruit (e.g., orange peel), was reported for infant male orangutans in captivity (Harrison 1962). There are also some reported cases of captive or rehabilitant orangutans and chimpanzees stimulating their own genitals with tools (Dixson 2012).

Masturbation, or self-stimulation of one's own sexual organs, is common among humans and nowadays is regarded as useful for healthy sexual development (Kaestle \& Allen 2011). Various nonhuman primates are also known to masturbate (Thomsen et al. 2003; Dixson 2012; Thomsen \& Sommer 2015); therefore, it may be a phylogenetically ancient behavior. However, there are relatively few studies that focus on masturbation among nonhuman primates in the wild (Thomsen \& Soltis 2004). Male chimpanzees (Pan troglodytes) are known to stimulate their own penises. Although Goodall (1989) noted that captive chimpanzees sometimes ejaculate by stimulating their own penises, it had not been observed to result in ejaculation in the wild conspecifics at Gombe. Similarly, at Mahale, it is common for males to "fumble with penis," but without it culminating in ejaculation (Nishida et al. 1999). Such fumbling of penis is done usually by hand (and sometimes by foot), but, thus far, I have found no reports of such penile-stimulating behaviors with tools, at least in wild chimpanzee populations.

\section{OBSERVATION}

The observation was made on the M group chimpanzees at the Mahale Mountains National Park, Tanzania (for the research site, see Nakamura et al. 2015). The "masturbation" event was recorded for a two-year old infant male named Peace, first born of Puffy (Figure 1). Puffy was born in the M group and has an elder maternal brother (i.e., uncle to Peace), Primus, who is the current alpha male of the $\mathrm{M}$ group.

On September 15th 2016, I was conducting ad libitum observations by following a party of chimpanzees since morning. At 11:04 h, I saw Puffy and Peace descending to the rocky riverbed of the Kasiha Valley. Many chimpanzees of the M group were feeding on Saba comorensis and Ficus vallis-choudae fruits along the valley while they slowly moved downstream. The Ficus fruits are of-

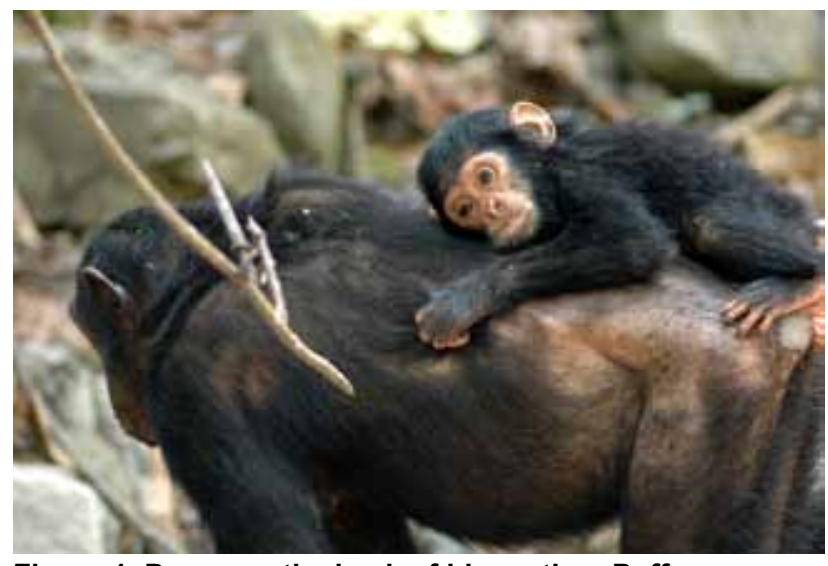

Figure 1. Peace on the back of his mother, Puffy

ten eaten by wadging (i.e., extracting juice by chewing and compressing the fruits; defined by Goodall 1989; see also Figure 2). After extracting the juice, the remainder is usually spat out as "a wadge."

At 14:36 h, Primus and Puffy seemed to have finished feeding and started grooming each other on the riverbed, while Peace sat nearby (Figure 3). Then at 14:47 h, Peace picked up a wadge of Ficus discarded by Primus and applied it to his genital area, inserting his erect penis into it and thrusting several times (Figure 4; Video 1 available at http://mahale.main.jp/PAN/2018/001.html). He successively used several wadges. At 14:52 h, he copulated with an estrus adult female, Omo.

\section{DISCUSSION}

Probably, no one would doubt that so called "sex toys," which some human males use for masturbation, are "tools" in the broader sense. The wadges into which

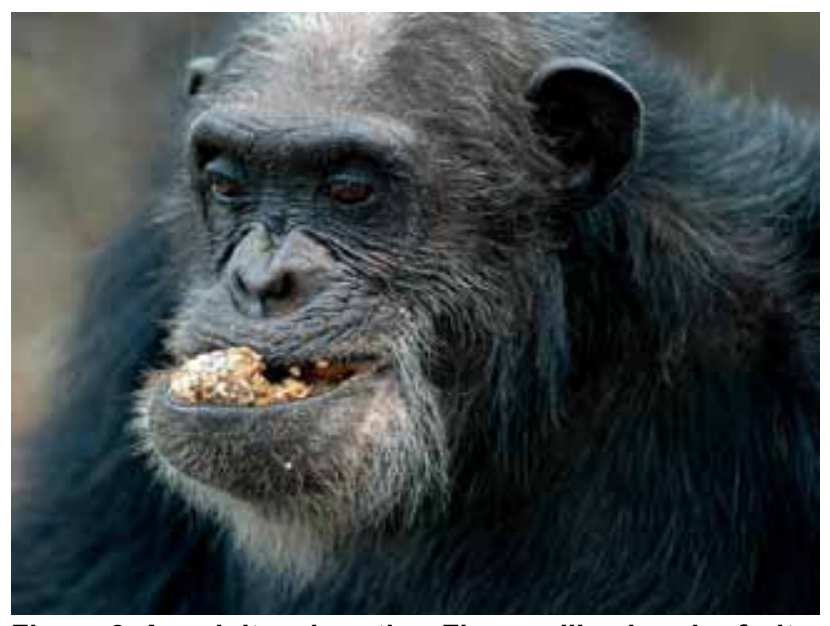

Figure 2. An adult male eating Ficus vallis-choudae fruits by wadging 


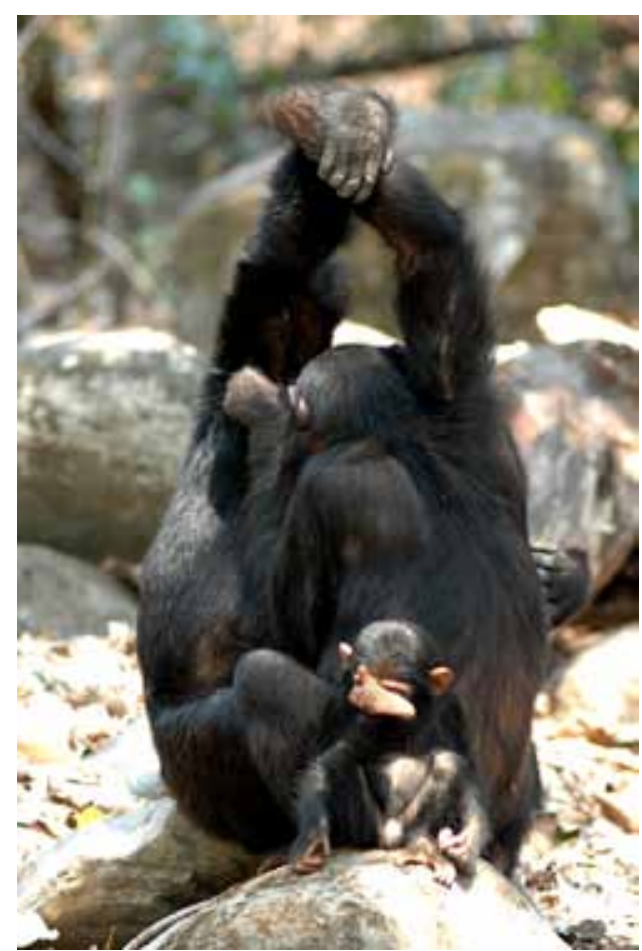

Figure 3. Primus (left) and Puffy (right) grooming each other while Peace sits in front

Peace inserted his penis apparently have the same function with those of "sex toys" even though the wadges were not purposefully made for that function. The wadges had just been discarded; therefore, they seem to have had moderate warmth, moisture, and softness that may give more pleasurable stimuli than those made with a hand or with rubbing his penis against ground. The wadges are also manipulable objects and thus meet the criteria of animal "tools" (Shumaker et al. 2011).

According to Morris (1971), the word masturbation appears to be a corruption of manu-stuprare, or "to defile with the hand," thus it primarily implies using a hand. Definitions of masturbation by macaque (Macaca spp.) males also include "manual rubbing" (Thomsen \& Soltis 2004) or "manual manipulations" (Dubuc et al. 2013). However, these cases may simply reflect the use of a hand or hands being observed, and if we think of human and nonhuman ape masturbation using tools, the use of hand may not necessarily be a condition of the definition of masturbation.

Some may consider that male masturbation potentially leads to ejaculation (though it may sometimes end before ejaculation). The fact that discussions of male masturbation are often done in strong connection with sperm competition (Thomsen et al. 2003) also implies that ejaculation is thought of as a basic and fundamental component of this behavior. Although behavioral definitions of male primate masturbation do not usually require ejaculation to occur (Thomsen \& Soltis 2004;
Dubuc et al. 2013), these studies clearly showed that the defined behaviors of these males did sometimes lead to ejaculation. On the other hand, in the case of Mahale chimpanzee males (including sexually mature ones), Nishida (2008) emphasizes that their penile fumbling "is not masturbation" because it completely lacks ejaculation. Considering that male masturbation requires ejaculation, as stated in the study by Nishida, the observed subject (Peace) cannot be stated to have masturbated.

Some authors say that it is inappropriate to call contact to/with sexual organs by infant primates as sexual (Mizuhara 1981). On the other hand, Takenoshita (2009) argues that some behaviors can be sexual even without ejaculation. It is difficult to discern whether or not an infant chimpanzee, which cannot ejaculate, had sexual pleasure by stimulating his own penis. At least, when a chimpanzee infant male inserts his erect penis into the vagina of a female and thrusts it (without ejaculation), the behavior is called "copulation" (e.g., Hasegawa 1990), the same term used for a mature male's almost identical sexual behavior. Hence, Peace's behavior may be regarded as sexual, despite lacking ejaculation. Peace copulated with an estrous female following his behavior involving wadges; hence, it seems that motivation underlying this behavior might have been similar to that underlying copulation with a female.

\section{ACKNOWLEDGMENTS}

I would like to thank the Tanzania Commission for Science and Technology, the Tanzania Wildlife Research Institute, and the Tanzania National Parks for the permissions to conduct field research at Mahale. I would also like to thank Dr. Ruth Thomsen, Dr. Kazuhiko Hosaka, and an anonymous reviewer for their helpful comments and suggestions on the earlier manuscript. The study was supported by the MEXT/JSPS kakenhi JP15H04429, \#4903 JP17H06381, and JP26284138.

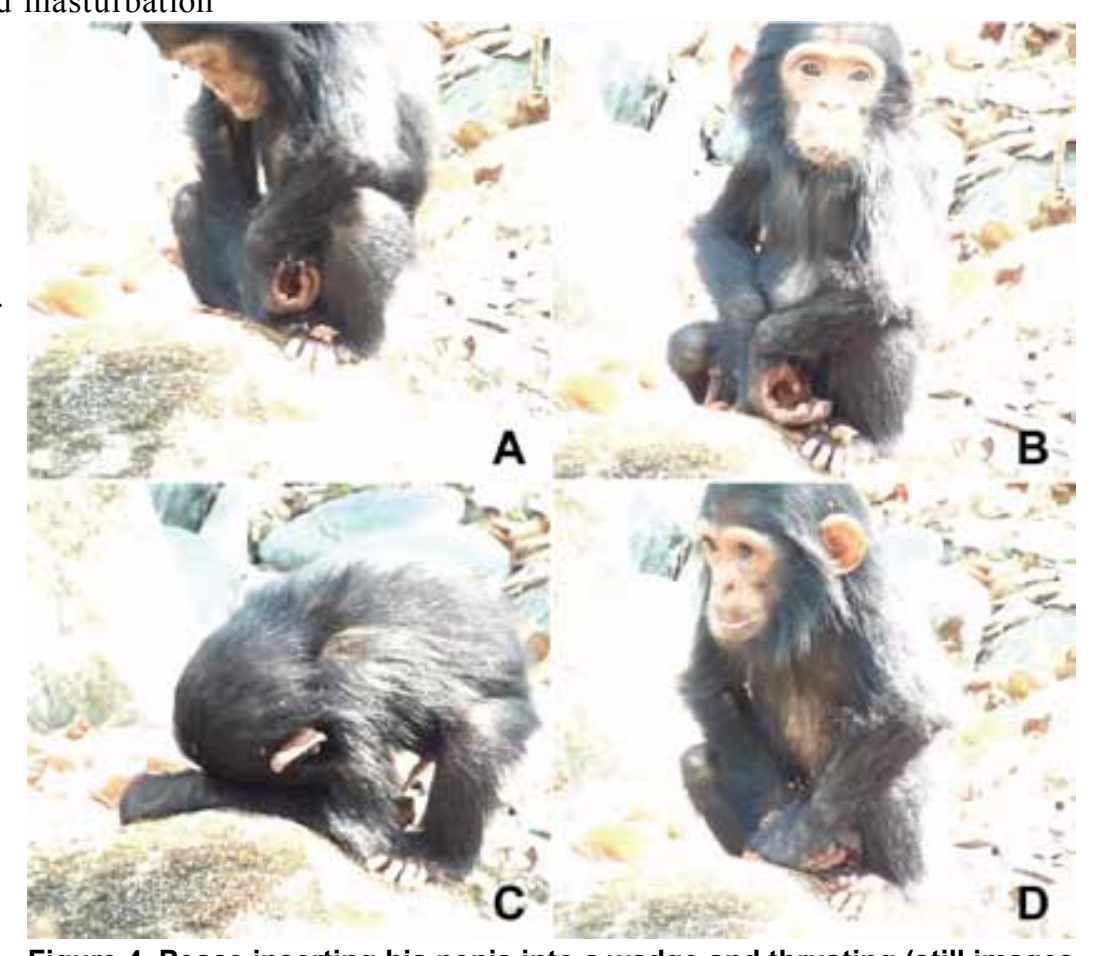

Figure 4. Peace inserting his penis into a wadge and thrusting (still images taken from video) 


\section{REFERENCES}

Dixson AF 2012. Primate Sexuality. Oxford University Press, Oxford.

Dubuc C, Coyne SP, Maestripieri D 2013. Effect of mating activity and dominance rank on male masturbation among free-ranging male rhesus macaques. Ethology 119 1006-1013.

https://doi.org/10.1111/eth.12146

Goodall J 1989. Glossary of Chimpanzee Behaviors. Jane Goodall Institute.

Hasegawa T 1990. [Mystery of promiscuous society: Sexual life of chimpanzees.] In: [Cultural Historiography of Monkeys.] Nishida T, Izawa K, Kano T (eds), Heibon-sha, Tokyo, pp. 371-388, in Japanese.

Harrisson B 1962. A study of orang-utan behaviour in the semi-wild state 1959-60. Int Zoo Yearb 3: 57-68. https://doi.org/10.1111/j.1748-1090.1962.tb03396.x

Kaestle CE, Allen KR 2011. The role of masturbation in healthy sexual development: Perceptions of young adults. Arch Sex Behav 40: 983-994.

https://doi.org/1001007/s10508-010-9722-0

Mizuhara H 1981. [Notes on Behavioral Theory of Japanese Macaques.] Dōbutsu-sha, Tokyo, in Japanese.

Morris D 1971. Intimate Behaviour: A Zoologist's Classic Study of Human Intimacy. Random House, New York.

Nakamura M, Hosaka K, Itoh N, Zamma K 2015. Mahale Chimpanzees: 50 Years of Research. Cambridge University
Press, Cambridge.

Nishida T 2008. [Society of Chimpanzees.] Tōhō Shuppan, Tokyo, in Japanese.

Nishida T, Kano T, Goodall J, McGrew WC, Nakamura M 1999. Ethogram and ethnography of Mahale chimpanzees. Anthropol Sci 107:141-188. https://doi.org/10.1537/ase.107.141

Shumaker RW, Walkup KR, Beck BB 2011. Animal Tool Behavior: The Use and Manufacture of Tools by Animals. The Johns Hopkins University Press, Baltimore.

Takenoshita Y 2009. [Sex by Japanese macaques: "Proceptivity" observed in homosexual behaviors.] In: [Anthropology of Sex.] Okuno K, Shiino W, Takenoshita Y (eds), Shunpū-sha, Tokyo, pp. 3-34, in Japanese.

Thomsen R, Soltis J 2004. Male masturbation in free-ranging Japanese macaques. Int J Primatol 25:1033-1041. https://doi.org/10.1023/B:IJOP.0000043350.75897.89

Thomsen R, Soltis J, Teltscher C 2003. Sperm competition and the function of male masturbation in nonhuman primates. In: Sexual Selection and Reproductive Competition in Primates. Jones CB (ed), American Society of Primatologists, Norman, pp. 437-453.

Thomsen R, Sommer V 2015. Masturbation (nonhuman primates). In: The International Encyclopedia of Human Sexuality (First Edition). Whelehan P, Bolin A (eds), Wiley-Blackwell, Boston. https://doi.org/10.1002/9781118896877 wbiehs289

Received: 4 October 2017

Accepted: 1 February 2018 